\title{
Scalp Pemphigus Vulgaris Mimicking Folliculitis Decalvans: A Case Report
}

\author{
Manal Bosseila ${ }^{1}$, Eman A. Nabarawy ${ }^{1}$, Mostafa A. Latif ${ }^{1}$, Sally Doss ${ }^{1}$, \\ Mona ElKalioby ${ }^{1}$, Marwah A. Saleh ${ }^{1}$
}

1 Dermatology Department, Cairo University, Egypt

Key words: pemphigus vulgaris, scalp, folliculitis decalvans, tufted folliculitis, dermoscopy, trichoscopy

Citation: Bosseila M, Nabarawy EA, Latif MA, Doss S, ElKalioby M, Saleh MA. Scalp pemphigus vulgaris mimicking folliculitis decalvans: a case report. Dermatol Pract Concept. 2019;9(3):215-217. DOI: https://doi.org/10.5826/dpc.0903a10

Accepted: December 10, 2018; Published: July 31, 2019

Copyright: $\odot 2019$ Bosseila et al. This is an open-access article distributed under the terms of the Creative Commons Attribution License, which permits unrestricted use, distribution, and reproduction in any medium, provided the original author and source are credited.

Funding: None.

Competing interests: The authors have no conflicts of interest to disclose.

Authorship: All authors have contributed significantly to this publication.

Corresponding author: Dr. Manal Bosseila, Dermatology Department, Kasr AlAiny Hospital, Manial, Cairo, Egypt. Email: manal.bosseila@ kasralainy.edu.eg

\section{Introduction}

Pemphigus vulgaris (PV) without mucosal involvement is quite rare. The scalp is commonly affected at presentation in $\mathrm{PV}$ and is frequently the first site of the disease [1].

\section{Case Presentation}

We present a case of PV mimicking folliculitis decalvans clinically and dermoscopically on its first presentation. A 40-yearold male patient presented with patchy alopecia, erythema, and follicular pustules on the scalp of 3 months' duration (Figure 1A). The patient gave a history of treatment with antibiotics and antifungals, with no improvement. There were no other lesions involving the skin or mucous membranes at the time of presentation. On using a handheld dermatoscope $(\times 10$ magnification), many of the characteristic trichoscopic features of folliculitis decalvans such as tufted folliculitis, perifollicular erythema, crusting, and follicular pustules were seen in this case (Figure 1B).
The diagnosis of folliculitis decalvans was suggested, although the presence of skin erosions and excessive peripilar casts did not coincide with this diagnosis. Histopathological examination revealed suprabasal acantholysis of surface epidermis and adnexal epithelium consistent with the diagnosis of PV that was confirmed using direct immunofluorescence.

Two weeks later, the patient developed extensive alopecia as well as acute widespread papules, erosions, and few blisters on his neck, axillae, inguinal folds, and arms. Mucous membranes were not affected (Figure 2A). Dermoscopically alopecia with evident erosions, tufted folliculitis, and extensive peripilar casts were seen (Figure 2B).

"Tufted folliculitis," "tufting," or "polytrichia" is the manifestation of a fibrosis-induced gathering of adjacent follicular structures, as well as a follicular retention of telogen phase hairs over multiple cycles, seen clinically as "doll's hairs" [2]. It was speculated that due to persistent bacterial infection superimposed on erosions of PV, an ongoing inflammatory process was induced, leading to tufted folliculitis [1]. This pattern has been previously reported in patients with long- 


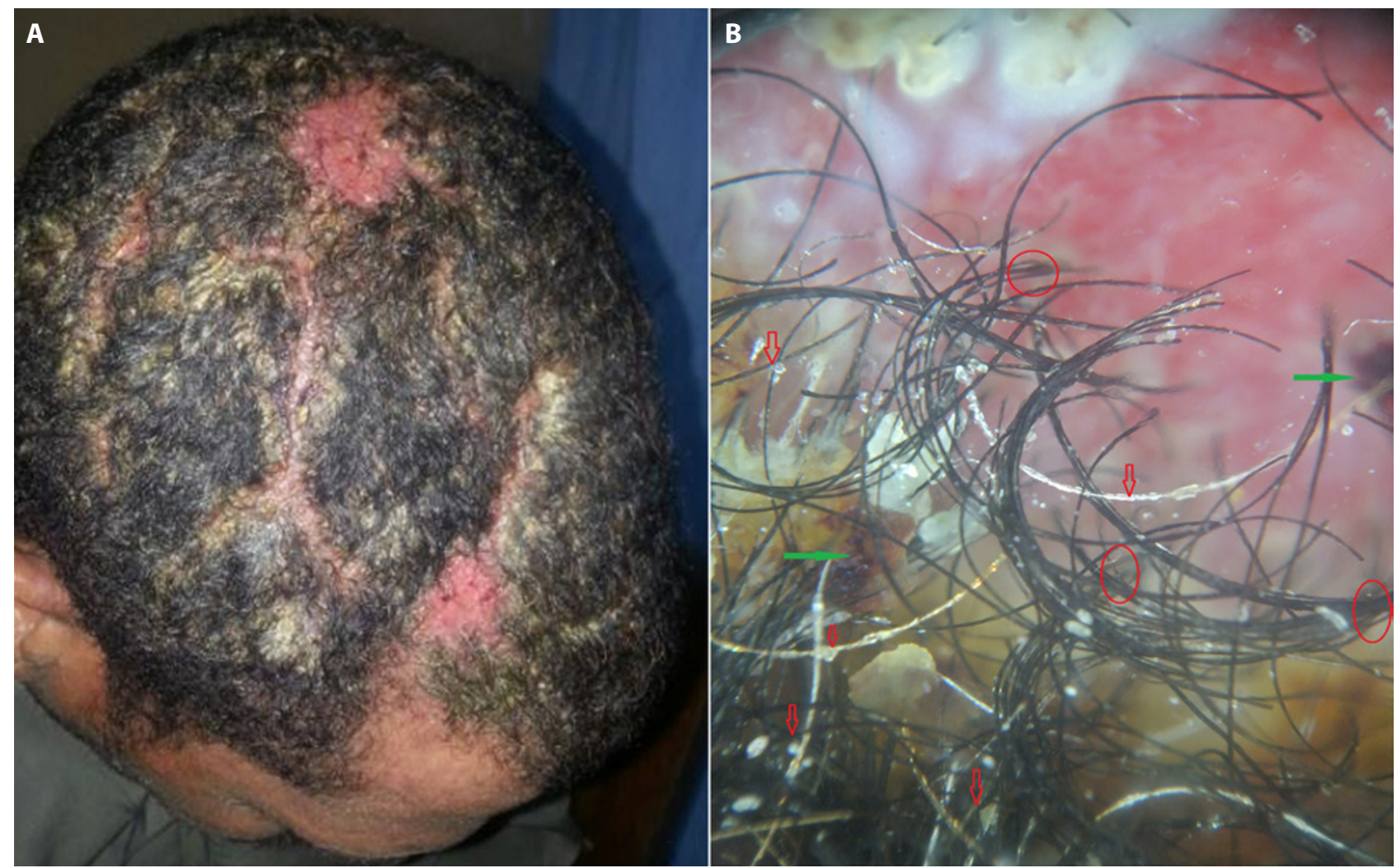

Figure 1. (A) Patchy alopecia with yellow crusting over the vertex and frontal parts of the scalp. (B) By trichoscopy: follicular tufting (red circles) with follicular pustules and acantholytic hair casts (red arrows). Erosions are minimal (green arrows) ( $\times 10$ ). [Copyright: (02019 Bosseila et al.]

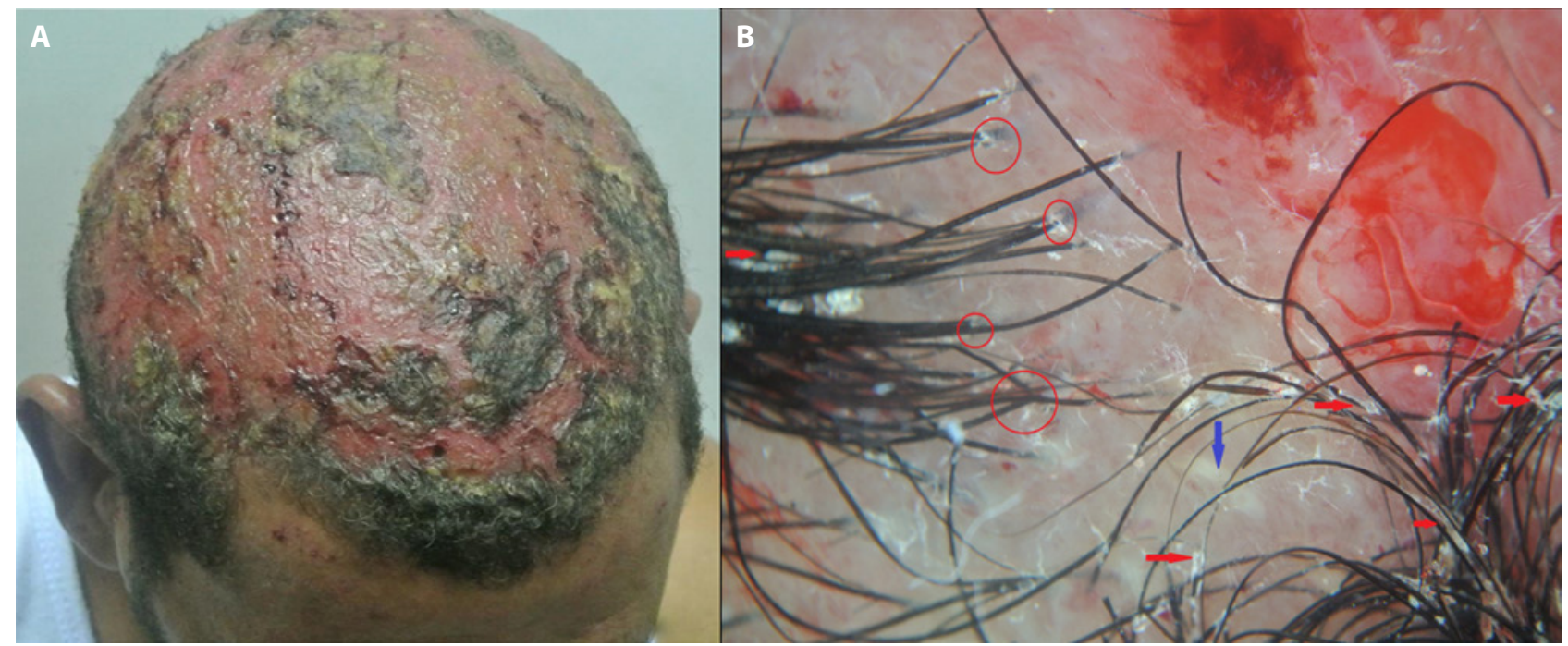

Figure 2. (A) Extensive hair loss 2 weeks later with visible erosions of the scalp. (B) By trichoscopy: multiple follicular tufting (red circles), acantholytic peripilar casts (red arrows) with larger areas of erosions on a pale pink background. Few shiny white localized areas of fibrosis are seen (blue arrows) (×10). [Copyright: @2019 Bosseila et al.]

standing disease duration [2]. Our patient had scalp lesions for only 3 months at the time of presentation.

\section{Conclusions}

It is noteworthy that the dermoscopic finding of multiple hair tufting in PV of the scalp was documented only in male patients, as reported previously in the literature $[2,3]$ and in our case as well. The peripilar casts sign was reported previously as movable tubular structures that envelop the hair shafts in PV. It was suggested that acantholytic hair casts should be considered as a dermoscopic diagnostic feature of outer root sheath separation in cases of PV of the scalp and to indicate disease activity as well [1]. On the other hand, using 
20- to 70-fold magnification to examine 26 cases of PV of the scalp, well-circumscribed hair casts were found in only 1 case, whereas other trichoscopic findings were observed, such as extravasations, yellow hemorrhagic crusts, and white diffuse scaling [3].

We propose that early cases of PV of the scalp may mimic clinically and dermoscopically the picture of folliculitis decalvans. The additional presence of tiny erosions and cylindrical casts around hair shafts by dermoscopy should draw the attention to the possibility of cutaneous PV.

\section{References}

1. Hadayer N, Ramot Y, Maly A, Zlotogorski A. Pemphigus vulgaris with loss of hair on the scalp. Int J Trichology.2013;5(3):157-158.

2. Ko DK, Chae IS, Chung KH, Park JS, Chung H. Persistent pemphigus vulgaris showing features of tufted hair folliculitis. Ann Dermatol. 2011;23(4):523-525.

3. Sar-Pomian M, Rudnicka L, Olszewska M. Trichoscopy—a useful tool in the preliminary differential diagnosis of autoimmune bullous diseases. Int J Dermatol. 2017;56(10):996-1002. 